\title{
The Effects of World War II on Economic and Health Outcomes across Europe
}

\author{
Iris Kesternich, \\ University of Munich \\ Bettina Siflinger, \\ University of Munich \\ James P. Smith, and \\ RAND \\ Joachim K. Winter \\ University of Munich
}

\begin{abstract}
We investigate long-run effects of World War II on socio-economic status and health of older individuals in Europe. We analyze data from SHARELIFE, a retrospective survey conducted as part of SHARE in Europe in 2009. SHARELIFE provides detailed data on events in childhood during and after the war for over 20,000 individuals in 13 European countries. We construct several measures of war exposure-experience of dispossession, persecution, combat in local areas, and hunger periods. Exposure to war and more importantly to individual-level shocks caused by the war significantly predicts economic and health outcomes at older ages.
\end{abstract}

\section{Introduction}

The Second World War (WWII) was one of the major transformative events of the 20th century, with 39 million deaths in Europe alone. Large amounts of physical capital were destroyed through six years of ground battles and bombing. Many individuals were forced to abandon or give up their property without compensation and to move on to new lands. Periods of hunger became more common even in relatively prosperous Western Europe. Families were separated for long periods of time, and many children lost their fathers. Many, including young children, would personally witness the horrors of war as battles and bombing took place in the very areas where they lived. Horrendous crimes against humanity were committed. Due to WWII, political and economic systems in many countries would be permanently altered.

In this paper, we investigate long-run effects of World War II on late-life economic and health outcomes in Western continental Europe (health, education, labor market outcomes and marriage). We explore several channels through which this war might have influenced individual lives, and document which groups of the population were most affected. Our research relies on retrospective life data from the European Survey of Health, Aging, and 
Retirement in Europe (SHARE) that have recently become available. SHARE covers representative samples of the population aged 50 and over in 13 European countries, with about 20,000 observations. We also collected external data on casualties, timing and location of combat action, yearly GDP by country, population movements, and male-female population ratios. To our individual-level analysis of the multidimensional effects of a major shock that affected life circumstances, we add new dimensions to a rapidly increasing literature that aims at explaining the causes of health and wealth gradients in labor and health economics (see Deaton, 2007; Smith, 2009a; Heckman, 2012).

SHARE not only measures major contemporaneous economic and health outcomes of adults over age 50 in these European countries, but includes retrospective modules meant to capture salient parts of early life experiences, including those related to the war. There simply are no micro economic panel data in either the United States or in Europe that have prospectively tracked people for that long a time period. ${ }^{1}$ The co-existence of current prospective data combined with retrospective data on key events that preceded the survey baseline opens up important new research opportunities not before possible, and not simply those associated with the WWII. Since the end of WWII, western continental Europe has had a rich and sometime tumultuous economic and political history, the effects of which on its residents are not well documented.

There is legitimate concern about the quality of recall data, particularly for time periods decades in the past. But that concern has been lessened by a realization that recall of events during childhood is better than for other periods of life, particularly if events are salient as they certainly are in this application. Smith (2009b) investigated several quality markers and showed that his childhood health instrument was successful in matching known secular trends in childhood illnesses decades in the past. ${ }^{2}$ Moreover, we will provide evidence in this paper that these recalled events in the SHARE retrospective about the war matched the historical record.

One aim of the paper is to illustrate how such retrospective life data can further our understanding of effects of early-life conditions as affected by large external shocks, such as a war. The existing literature measuring impacts of macro-events mostly used "natural experiments" such as wars or famines to study effects of early-life conditions at the aggregate level. Largely due to data reasons beyond their control, the studies of which we are aware could not use individual-level measures of whether a particular person was affected by the war and through which channel. Retrospective life data, such as those from SHARE, contain detailed information and provide the opportunity of studying that issue.

Analyzing different outcomes is a first step in understanding the channels and mechanisms by which wars affect people's lives. Another possibility is using different measures of war exposure such as the closeness of combat. We construct such measures from external data

\footnotetext{
${ }^{1}$ PSID, the longest micro-economic panel, began in 1968 more than 20 years after WWII. The longest running European microeconomic panel, GSEOP, began in 1984, almost 40 years after the war.

${ }^{2}$ There was also no evidence of backwards attribution of new episodes of adult health problems into a revaluation of childhood health Adult respondents whose health deteriorated between PSID waves were no more likely than before to say their childhood health was not good or to cite additional childhood health problems (Smith, 2009b)
} 
sources. In addition, SHARE data contain retrospective questions on several possible channels of war exposure: hunger, the absence of the father, dispossession, and persecution.

Given the scale of the war and number of ways it fundamentally changed the world, the existing economic literature using WWII as a natural experiment is surprisingly thin. Moreover, the literature that does exist using WWII is relatively recent and more American in context than European. This may reflect the fact that the popularity of "natural experiments' framework in economics itself post-dated WWII by many decades. Still, it does suggest that excellent research opportunities remain, especially given the wide diversity of European experiences in WWII.

This paper is divided into six sections. The next highlights the main attributes of SHARE data and the additional data we collected for this research. Section III sets the stage for our analysis by presenting evidence of possible changes on which long-term effects of WWII may operate. The fourth section summarizes statistical models that capture impacts of the experience of WWII on individual adult labor market, demographic, and health outcomes. We also present our models of the influence of the war on some of the primary pathways through which it had long lasting impacts-hunger, dispossession, the absence of a father, and marriage. The final section highlights our main conclusions.

\section{SHARELIFE Data}

\section{A. SHARE and Retrospective Early-life Data from SHARELIFE}

SHARE is a multidisciplinary cross-national panel interview survey on health, socioeconomic status, and social and family networks of individuals aged 50 or over in continental Europe. The original 2004/2005 SHARE baseline included nationally representative samples in 11 European countries (Denmark, Sweden, Austria, France, Germany, Switzerland, Belgium, Netherlands, Spain, Italy, and Greece) drawn from population registries, or from multi-stage sampling (http://www.share-project.org/). For these countries, a second wave of data collection took place in 2006, and the third wave of data collection on this panel (SHARELIFE) was completed in 2008.

In addition to a standard set of demographic attributes (age, marital status, education), SHARE data include health variables (self-reported health, health conditions, health behaviors), psychological variables (e.g., depression and well-being) economic variables (current work activity, sources and composition of current income, and net wealth (including housing, cars, and all financial assets (stocks, bonds, and cash) minus all debts)).

SHARE's third wave of data collection, SHARELIFE, collected detailed retrospective lifehistories in 13 countries (Poland and the Czech Republic were added in wave 2) in 2008-09. SHARELIFE was based on life history calendar (LHC) methods. The interview starts with the names and birth dates of the respondent's children (and other information about them including any deaths), which is followed by a full partner and residential history. This information is used to aid in dating of all other events.

The information in the life history includes family composition and type of home (number of rooms, running water, toilet, etc), number of books, and occupation of father. These 
measures were used to create an index of childhood SES at age 10. A childhood health history is also included based on the Smith module included in the PSID and HRS that queries about individual specific childhood diseases and an overall subjective evaluation of childhood health status (Smith, 2009b). In addition, respondents are asked about childhood immunizations and hunger during childhood. Adult health histories and job and income histories were also collected. Moreover, SHARELIFE provides detailed data on withincountry region of residence and housing during the full life of respondents (childhood and adulthood).

\section{B. Other Data Sources}

In addition to SHARE data, we also use external data sources to identify aggregate channels of war-affectedness. Since WWII affected not only countries differentially, but also regions within countries, we constructed data on combat operations using sources from military history (Ellis, 1994). Using maps of within-country regions for each month during the war, we documented whether armies engaged in battle in that place at that time. We combined these data with information about the region in which respondents lived during each year of WWII and use it as one measure of individual war exposure.

Since we analyze data over a time period of 50 years, we also have to account for countryspecific economic performance that may have affected childhood circumstances differently. We therefore use GDP data, which are available for each European country (Maddison, 2011). We also used external data on country-specific civilian and military causalities associated with WWII, population movements, and the sex ratio. Table 1 contains definitions of variables derived from SHARE and SHARELIFE that will be used in our analysis in this paper. Appendix Table A provides a parallel list of variables constructed from external data sources with a documentation of the source that was used.

\section{The Channels of Long-term Effects of WWII}

This section presents descriptive data and reviews the current literature on possible major channels through which WWII might have affected people's lives well into their older years. The channels include future per capita income growth of countries affected, mortality, changing sex ratios, absence of a father, periods of hunger, migration, dispossession, and persecution. This section is used to motivate the rationale for analyses pursued in section IV.

\section{A. Per Capita Income Growth}

If wars alter long-term economic growth, they would permanently depress economic prospects of future generations. Warfare reduces capital stock through the destruction of infrastructure, productive capacity, and housing through bombing and fighting, and results in a relocation of food and other production into military production. It obviously destroys human capital—but the real question for our analysis is will there be catch-up growth, or will the destruction show up many decades later?

Based on Harrison (1998), table 2 displays GPD per capita of some of the major countries involved in the war relative to that of the US at key illustrative dates. The immediate impact of WWII was apparently quite destructive for the countries involved, especially so for those 
on the losing side—Germany, Japan, and Italy—presumably reflecting their much larger losses in both physical and human capital during the war. However, by 1973 and certainly by 1987, the European 'losers' actually had higher per capita growth than European 'winners'. What appears to be essential in the long-term was not whether a country was on the winning or losing side, but whether or not they transited to democracy and open-market economies. ${ }^{3}$ The poor performance of USSR countries illustrates that point. ${ }^{4}$

\section{B. Mortality}

In 1939, there were about 2 billion people in the world. The best estimates indicate that between 62 and 78 million of them would die due to WWII-more than $3 \%$ of the world's population. While earlier wars also resulted in deaths of civilians, ${ }^{5}$ civilians were particularly heavily affected by WWII with about half of the WWII European casualties being civilians. Among civilian deaths, between 9.8 and 10.4 million civilians were murdered for political or racial reasons by the Nazi regime (Auerbach, 1992). Deaths due to the war were very unequally distributed across countries, whether they were military deaths due to combat, civilian deaths, or the holocaust. Figure 1.A displays the fraction of the 1939 population who died in a large array of affected countries. Among European countries covered by our data, Germany and Poland bore the brunt of these casualties. In contrast and for comparative purposes only, American causalities in the European and Asian theatres combined were a bit over 400,000 , the overwhelming majority of whom were soldiers. Similarly, total deaths in the UK are estimated to be about $450,000,15 \%$ of whom were civilians.

Figure 1.B displays total number of deaths by type in the same countries. Deaths were highly concentrated in Germany and Poland where deaths measured around 5 million in both countries. In Germany, there were almost as many civilian deaths as military ones, while in Poland civilian deaths including the holocaust are by far the dominant ones. In many of the remaining countries in our data, deaths due to WWII are measured instead in the hundreds of thousands, but still often amount to a large fraction of the pre-war populations in several other countries, particularly Austria and the Netherlands. The other European countries that stand out are those that would comprise most of the Soviet Union, where one in seven perished in the war with about 10 million military deaths and 13 million civilian deaths. Unfortunately, data on these countries are not part of the SHARE network of European countries. 6

\footnotetext{
${ }^{3}$ Waldinger (2012) demonstrated one micro channel on human capital, the loss of Jewish university professors in Germany due to WWII. He shows that the productivity of those departments in Germany which lost a relatively high share of their professors was permanently lowered, while shocks to physical capital due to Allied bombing had returned to their old growth path by the 1960s. More generally, to make up for investments in human capital takes years, while plants and factories can be repaired and replaced much more quickly.

${ }^{4}$ A related issue is the impact of WWII on population growth in countries and affected cites. In spite of deaths of large numbers of civilians in WWII, the existing evidence indicates that affected cities went back to old population growth paths in Western Germany and Japan (Brakman et al., 2004), while city growth, but also economic growth, was permanently depressed in East Germany and the Soviet Union (Acemoglu et al., 2011; Brakman et al., 2004).

${ }^{5}$ For example in WWI there were 16 million total deaths of which almost 10 million were military deaths. Most of the civilian deaths in WWI were due to famine and disease.

${ }^{6}$ While we concentrate for data reasons primarily on the effects of World War II in continental Western Europe, the War's impact was just as stark in the Asian theatre. The two countries most directly affected in terms of number of causalities were Japan and China. About 2 million Japanese soldiers died in the war alongside up to a million Japanese civilians-about $4 \%$ of the pre-war Japanese population. The total number of deaths in China is believed to range between 10 and 20 million, with more than $70 \%$ being civilians.
} 


\section{Sex Ratios and Absence of Father}

Mostly men died during the war, producing low male/female ratios in Europe after the war as well as absence of many fathers during respondents' childhood years. Since the male bias in deaths was concentrated among soldiers as civilian and holocaust fatalities were largely gender neutral, it is countries in figure 1 who experienced many military deaths that were most affected. With 3 million military deaths, the most affected country in our data was Germany.

The top left-hand side of table 3 shows one immediate demographic consequence of the war by listing by country and period when one was age 10 the fraction of individuals who had a biological father absent when they were 10 years old. Once again, the largest effects took place in the war-ravaged countries of Austria, Germany, and Poland. In Austria and Germany, about one in four children lived without their biological fathers when they were age 10 during the war. The legacy persists into years after the war since many who were age 10 during 1950-1955 had fathers who died during the war. In Germany, almost a third of those age 10 in these years were not living with their biological father. Absent father rates fall sharply in the post-1955 years since these children were born after the war. We observe war spikes in other countries as well (Italy, France, Denmark, and Belgium), but the contrasts with the pre- and post-war years are not as dramatic.

Sex ratios before, during, and after the war are contained in the bottom-right half of table 3 . In Germany, the sex ratio dropped from 0.96 in 1939 to 0.72 men per women in the 15-45 age group after the war in 1946. Thus, many women did not marry, and many children grew up without a father. Even after the war, about 4 of the 11 million German prisoners of war remained in captivity, and the last 35,000 German soldiers returned from the Soviet Union in 1955 which further compounded the problem of absent fathers (Wehler, 2008).

\section{Hunger}

One channel by which WWII might have affected long-run adult health and SES outcomes is hunger. World War II caused several severe hunger crises which led to many casualties, and may have had long-term effects on the health of survivors. For example, since the beginning of the German occupation in Poland, the nutritional situation of the non-German population was poor. The average caloric intake for the Polish population was about 930 calories in 1941. The situation was worst in the Warsaw Ghetto where average food rations were limited to about 186 calories per day in 1941.

Similarly, in the fall and winter 1941/1942, Greece was struck by a severe famine with about 100,000 to 200,000 deaths (Hionidou, 2006). In WWII, Greece was under Bulgarian, German, and Italian occupation. The famine was mainly caused by three factors: (1) occupiers imposed a naval blockade; (2) prices to farmers were fixed at such low levels that they were not willing to market their products; (3) mobility between different regions of the country was reduced due to occupation. The nutritional situation returned to acceptable levels towards the end of 1942. Neelson and Stratman (2011) use Cohort Data to show that undernourishment of children who were 1 or 2 years old at the time of the famine had a significantly lower probability of being literate or to complete upper secondary education. 
A combination of a food blockade and a harsh winter led to a severe hunger crisis in winter 1944/1945 in the Netherlands. About 20,000 deaths, mainly among elderly men, are attributed to this famine. The famine ended with the end of the German occupation in May 1945. The Dutch famine has been extensively studied because it affected an otherwise wellnourished population at a very specific time and region. Individuals exposed to this famine in utero are shown to suffer from cognitive and mental problems and addiction (Neugebauer et al., 1999; Rooij et al., 2010), diabetes and coronary heart disease, and they also perform worse regarding anthropometric and socio-economic indicators (Almond and Currie, 2011).

Germany suffered from hunger between 1945 and 1948 when the food supply from occupied countries ceased. In the US occupation zone, the Office of Military Government for Germany established a goal of 1550 calories per day in 1945, but in the first months of occupation, this goal often could not be met. There were regions where average calories per day were around 700 (Gimbel, 1968). Death rates raised by the factor 4 for adults and 10 for infants during this period. With a good harvest and currency reform in June 1948, nutritional shortages were overcome (Zink, 1957).

Figure 2 demonstrates that hunger episodes during the war were much more severe in war countries than in those countries that did not participate in the war. We also see that there was a great amount of diversity in periods of hunger within war countries. Hunger is more common in regions where combat took place within war countries. Finally and not surprisingly, the experience of hunger was far more common among those of low socioeconomic background as a child. With respect to hunger, our analysis shows that the individual-level reports in SHARELIFE match well historical information on the timing and location of hunger episodes we collected from historic sources. To illustrate, in figure 2 the Greek hunger spike occurred in 1941-1942, the Dutch in 1944-45, and the German in 1946-1947.

\section{E. Dispossession, Persecution, and Migration}

SHARELIFE documents the extent of the experience of dispossession of property linked to WWII and its aftermaths. Dispossession was often associated with persecution and resulted in geographic displacement of populations during and immediately after the war. A further advantage of SHARELIFE is that we can observe where and when individuals moved during their lifetimes, including the wartime period.

There were three main periods when people were forced to flee their homelands. During WWII, millions of Jews, but also opponents of the Nazi regime, were expropriated, and often sent to concentration camps and were murdered there. Second, the end of WWII was associated with dramatic border changes in Eastern Europe. These border changes induced millions of individuals to leave their places of residence and flee to other parts of Europe. The Soviet Union annexed territory from some of its neighboring countries, inter alia from Czechoslovakia, Germany, and Poland. Poland in turn received one part of pre-war Germany in compensation. Those Poles having lost their homes in the part occupied by the Soviet Union were moved to the new part, so Poland and with it millions of people were moved westwards. 
Figure 3 shows inflows and outflows of populations during and after the end of WWII into the new states in their new borders. Germany lost about one quarter of its territory. About 2 million people have been estimated to have died on the flight. After the war, the remaining territory of Germany was divided into four occupational zones. About 4 million people fled from the approaching Soviet armies to the British and US zone where the occupation was less severe. In Germany, destroyed cities had to accumulate millions of ethnic Germans from other parts of Europe. A further wave of dispossessions happened in Eastern countries after WWII when private property was nationalized in the socialist and communist economies. Even in France, there was a wave of nationalizations at the end of WWII. Mainly banks, energy, and transport firms were nationalized, but there were also some expropriations which happened as penalty for cooperation with the Nazi regime.

The bottom left-hand side of table 3 displays dispossession rates in our SHARE countries by time period with the final column indicating the percent ever dispossessed. Figure 4 complements the data in table 4 by showing the percentage of dispossessed individuals in SHARELIFE for the foreign and native-born populations. In the Czech Republic, Germany, and Poland more than $5 \%$ of respondents experienced dispossession during their lifetime. For respondents living in Germany and Poland, dispossession happened more frequently during the war period, while they happened after the war in Czechoslovakia. Dispossessed individuals in our sample are over proportionally born outside of the current borders of their country. Analyzing countries of origin, many of them came from Eastern Europe, thus they most probably lost their property with the big wave of nationalizations after WWII. Not surprisingly, it is the foreign-born living in our SHARE countries who were most likely to be dispossessed.

\section{WWII and Individual Outcomes: Analysis of SHARELIFE Data}

Based on the descriptive data and review in the prior section, we find enormous variation even among war countries in the immediate impact of WWII. Long-term economic or population growth rates seem unlikely to be a primary pathway through which the war's influence took place. Instead, changing gender ratios induced by differential male mortality in the war appear to be a more plausible pathway operating both through absence of fathers and difficulties faced by women in marrying. Hunger and immediate and long-term stress created by battles, dispossession, and persecution would also appear to be plausible pathways that could impact adult health, both physical and mental, and our later life measures of adult SES.

\section{A. Measures of War Exposure}

To analyze long-term impacts of WWII on health and economic outcomes, we use the fact that different countries in Europe and different people in those counties were differentially affected by WWII at different points in time. To study effects on adult outcomes, we use two indicators of being affected by World War II: (a) that one lived in a war country during the war period, and (b) that one was exposed to combat in the area within a country in which one lived during the war. Our first measure essentially creates a war dummy equal to zero for everybody in a non-war country (Denmark, Switzerland, and Sweden), and for everybody born after the war period no matter what country they lived in. Alternatively, it is 
equal to one for everybody alive in a war country (Austria, Belgium, Czech Republic, France, Germany, Greece, Netherlands, and Poland) during the war period. The war period ends in 1945 for all war countries, while it includes 1946 to 1948 in Germany and Austria, when they were under allied occupation. For these countries, the war period ended with the currency reform in Germany in 1948. Individuals could certainly have been affected by the war even if they were born after the war, but the channels we emphasize in this papercombat, hunger, dispossession, persecution, and the absence of a father-were more likely to have affected those who lived during the war.

Our second war measure involves constructing a variable indicating whether there were combats and how many combats occurred in the region within the country in which the individual lived during WWII. Thus, in the war countries, we create two dummy variables based on the number of months of exposure the respondent had to combat in the place they lived during the war -0 to 2 months of exposure to combat and 3 or more months of exposure to combat. The purpose of this variable was to test whether actual exposure to combat was an important mechanism for the war effects that we estimate below.

Table 4 provides the list of SHARE countries that are part of our analysis with the sample sizes of those SHARELIFE respondents who experienced the war and those who had no direct experience of war. We did not include Spain in our analysis since Spain experienced a civil war in the late 1930s, so a distinction between whether Spain is a war country or not is very ambiguous. The results were not significantly different if Spain was included.

\section{B. Micro-level Regressions of Adult Health and SES Outcomes}

We next turn to our statistical modeling of whether individuals' experiences during WWII predict their health and socio-economic status in their later adult life. For all of our later-life health and SES outcomes and channel outcomes, our estimating equation takes the form

$$
Y_{i t c}=\beta_{1} * \operatorname{war}_{i t c}+\beta_{2} * \operatorname{male}_{i}+\lambda_{t}+\eta_{c}+\varepsilon_{i t c}
$$

where $Y_{i t c}$ is the late-life outcome of respondent $i$ born in year $t$ and living in country $c$. Male indicates a respondent was male. War is one of our two measures of war exposure outlined above, which vary by country (or region within a country) and year of birth. Because there may be unmeasured country and year effects associated with these outcomes, $\lambda_{t}$ is a full set of year of birth dummies and $\eta_{c}$ is a full set of country dummies. $\varepsilon_{i t c}$ is a random error term. Since error terms within country and within year may be correlated, we used the cluster option in STATA.

Our principal interest is to obtain estimates of $\beta_{1}$ —the 'war' effect in addition to birth-year and country effects. We estimate reduced form models using our two War variables on later adult life health and SES outcomes and the principal channels of war. We consider several adult dependent variables all measured in 2009, the year of SHARELIFE. Health outcomes include prevalence of diagnosed diabetes and heart disease, body height in centimeters (a summary measure of early-life health conditions), whether an individual is depressed using a dummy variable for presence of at least four symptoms on the EURO-D scale, and self- 
reported health status. Self-reported health status is recorded on a scale excellent, very good, good, fair, and poor which we have translated to a scale from one to five with five the best health status. Our adult SES and economic outcomes include log of household net worth, whether the individual was ever married, and life-satisfaction in 2009. SHARE respondents are asked "On a scale from 0 to 10 where 0 means completely dissatisfied and 10 means completely satisfied, how satisfied are you with your life?" We model this outcome as a score from $0-10$.

We have two education measures in SHARE. The first is obtained from baseline SHARE in 2004 and, in an attempt to make the education variable comparable between individuals in the same country, assigns a standardized year for each education value. For example, university graduates in a country would be assigned a 16 . The second education variable is available in the second SHARE wave and is equivalent to the actual number of years spent in education. We use the second measure because Poland and the Czech Republic were not part of baseline SHARE and for those two countries the first measure is not available. However, we hypothesize that WWII may have disrupted education for many respondents and resulted in a longer time to complete a given level of education. To test that hypothesis for the sub-sample of respondents who have both measures of education from the second and first SHARE waves, we estimated a model that amounts to the difference between the two education measures (the second-wave education minus the first-wave education variable).

Figure 5 displays the association of three of our key outcomes-education, self-reported health, and depression — with time period of birth using three sub-sets of countriesGermany and Austria combined, other war countries, and the non-war countries. These outcomes are each expressed as the difference between each of the first two kinds of war countries minus the outcome in the non-War countries. For all three outcomes, the outcomes deteriorate relative to the non-war countries for those born at a time they would experience war.

Table 5 summarizes results obtained for adult health outcomes and table 6 for adult SES outcomes. We present regressions in the A panels that use only the aggregate war exposure measures and in panel B the measure that distinguishes between very limited exposure to combat (two months or less, including zero) or an more extensive combat exposure (three or more months) with the left-out category being not exposed to war at all. In terms of righthand side variables, there are no missing values for gender. If the outcome in any particular model is missing, this observation was not included in that specific model. Missing values in our outcomes are relatively rare. In terms of main channels (dad absence, dispossession, hunger, and persecution), missing values are in the order of one in a thousand observations.

Consistent with the literature, men have higher levels of adult diabetes and heart disease, lower levels of depression, and report themselves in better subjective health than woman do (Banks et al., 2010; Smith, 2007). Our principal concern involves estimates for aggregate war and combat variables. Living in a war country during the period of WWII is consistently statistically significantly associated with higher levels of adult diabetes, being more depressed, and reporting one's subjective health as worse. Being in a war country during the 
war increased the probability of diabetes in later life by 2.6 percentage points and depression by 5.8 percentage points while decreasing self-reported health by 9.4 percentage points. These increases are all high relative to baseline rates (Appendix Table B). Estimated effects on heart disease and height are not statistically significant.

The B panel of table 5 displays results for months of combat exposure variables-number of months of exposure respondents had to combat in the place they lived during the war in war countries using 0-2 months of exposure to combat and 3 or more months of exposure to combat. These results basically parallel those obtained for the war variable in both direction and magnitude-those with combat exposure were more likely to have diabetes as an adult, were in worse self-reported health, and were more likely to be depressed. The results are weaker for heart problem although 3 or more months of combat exposure increases the likelihood of heart disease as an adult and is statistically significant at the $10 \%$ level.

Table 6 repeats the same type of models for adult economic outcomes in 2009. Not surprisingly for these generations, compared to women men achieve more years of schooling, have higher net worth, are less likely to marry, and have higher levels of life satisfaction-common findings in the literature. Our measure of war exposure is strongly associated with all these SES outcomes, except ln Net Worth. Those in a war country during the war achieved about three-tenths of a year less education ${ }^{7}$ and achieved lower levels of life satisfaction (about a third of a point lower relative to a mean of 7.6) as older adults. The education difference model suggests that war makes respondents take longer (a third of a year) to reach a given level of education. Similarly, this exposure to war reduced the probability of women being ever married (about three percentage points) but not the marriage probability for men, consistent with the relative scarcity of men due to war. In contrast, ln household net worth is not associated with the wartime experience suggesting that this outcome mainly depends on post-war savings behavior and trends in asset prices. The war combat models in the B panel of table 6 produce roughly similar results in direction and magnitude of these outcomes.

One purpose of our combat variables was to test whether the actual exposure to combat was an important mechanism for the war effects that we estimate above. With the sole exceptions of adult depression (table 5) and live satisfaction (table 6), the estimated magnitude of the worse adult SES and health outcomes appear to be about the same amongst those with large or small exposures to actual combat. ${ }^{8}$ This suggests that experiencing combat and battles

\footnotetext{
${ }^{7}$ Ichino and Winter-Ebmer (2004) compare educational outcomes from cohorts affected by the war in Austria and Germany to cohorts in Switzerland and Sweden, using the main economic datasets with information on education and earnings in the countries. They find that the loss of schooling is about a fifth of a year compared to the following cohort. They suggest that the mechanisms are closing down of religious schools, absence of teachers due to the war, absence of students due to escaping bombing, and actual destruction of schools. Akbulut-Yuksel (2009) uses GSOEP to identify effects of destruction of German cities through bombing on schooling. She finds that destruction caused children to attain 0.4 fewer years of schooling. Her estimates suggest that this schooling reduction is mainly due to physical destruction of schools and the absence of teachers. Jürges (2011) uses the Micro-Census to analyze impacts of nutritional shortages in Germany on educational outcomes. He estimates a drop in educational achievements (having more than basic education) of about 5 percentage points for a baseline risk of about 30\%. His suggested pathway is nutritional deprivation in utero. Our result of about a third of a year of schooling lies between the estimates of Ichino and Winter-Ebmer and Akbulut Yuksel, but is lower than those of Jürges. However, we include a different set of countries, and not all of them were equally strongly affected by WWII as Germany was.

${ }^{8}$ For the two exceptions-depression and life satisfaction-the effect of three or more months of combat greater than $0-2$ months is statistically significant at the $1 \%$ level.
} 
close by to where you lived during the war are not the primary mechanism by which these war effects operate. The exceptions are of interest since it seems reasonable that frequent exposure to combat is associated with adult depression and lower levels of life satisfaction as the vivid memories of that experience persist into adulthood.

\section{Selection Effects}

As in any such analysis, there are issues of possible selection effects due to fertility, mortality, and migration that may have biased our estimates. The concern with selective fertility is that high-SES mothers reduced their fertility more during the war, which on average would lead to less healthy babies. SHARE does not contain variables on education of parents so we used instead our measure of childhood SES, acknowledging its possible endogenity. We examined fertility in SHARE in three time periods by SES-pre-war (before 1939), during the war (1939-1945), and post-war (>1945). Childhood SES was split at the median.

\begin{tabular}{lccc}
\hline \multicolumn{4}{l}{ Mean Number of Children per Women } \\
Median SES split & pre-War & During War & Post-War \\
Low SES & 1.28 & 1.43 & 2.47 \\
High SES & 1.11 & 1.25 & 2.25 \\
\hline
\end{tabular}

In all three periods, fertility is highest in the low-SES groups. But differential changes by SES in fertility across these three time periods do not seem large enough to be producing our results. Comparing pre-War and during-War periods, there was about 0.14 increase in fertility for both low-SES and high-SES groups. Similarly, comparing post-war to duringwar periods, average fertility rose by about one child in both SES groups. Moreover, when we added childhood SES measures to our models, which should partly control for any selective fertility associated with the war, our estimates of the long-term effects of war did not change much.

Individuals in our analytical sample are those still alive in 2009 so they are a selected sample of the population that experienced WWII. To the extent that those more affected are less likely to have survived, our results should understate the full effects of war on long-term health and SES outcomes. A more complicated issue concerns differential mortality by SES induced by the war. If mortality due to the War was much higher in low-SES groups (whose health would have been worse anyway), we would further understate health effects of War. We examined data on age of death of father by SES by whether one lived in a war or nonwar countries, and by whether you experienced the war as a child (born before 1946). Once again, dividing SES at the median we found the following for the mean age of death of father. Those born after 1946 who did die should be younger but the key comparison is differentials by SES. 


\begin{tabular}{lcccc}
\hline & \multicolumn{3}{c}{ Age of Death of Fathers } \\
Country & \multicolumn{2}{c}{ Low SES } & \multicolumn{2}{c}{ High SES } \\
\hline \multirow{3}{*}{ Non-war } & 73.76 & 72.89 & 73.73 & 72.95 \\
War & 71.22 & 70.87 & 70.67 & 70.36 \\
\hline
\end{tabular}

For non-war countries, we find that in comparing pre- and post-1945 that the age of death of father decreased by .8 of a year in both low- and high-SES groups. Using the same comparison, the age of father fell by .4 of a year in the war countries, but this was approximately the same for the low- and high-SES groups. Once again, this degree of selection does not seem large enough to be driving our results.

Because of population shifts, especially inflows documented in figure 3, we confined our analysis to the native-born in each country. Among countries in our data, figure 3 shows that outflows were significant only in Czech Republic, Poland, and Germany. Since it was not encouraged by receiving countries, migration during and after the War was quite difficult in Europe. But there was some migration and one must allow for the possibility that selective migration may influence our estimates on war effects especially for these three countries. Of course, people could have temporarily left combat areas as combat was taking place but stayed inside the same country, which should lead to an understatement of combat effects.

\section{Models of Channels of War}

We next turn to our estimates of how the micro pathway channels we highlighted abovehunger, dispossession, persecution, and the absence of father-are related to the experience of WWII. SHARELIFE respondents were asked 'Looking back on your life was there a period of time during which you were hungry?' If the answer was yes, they were asked when this occurred. Individuals in SHARE are also asked "whether they or their family were ever dispossessed of any property as a result of war or persecution," and if yes the date of that dispossession. They were also asked whether they had ever been victims of persecution because of their political beliefs, religion, nationality, ethnicity, sexual orientation, or their background. Unfortunately, no time period for that persecution was asked. Finally, the absence of the father is defined as the absence of the biological father at the age of 10 . About $8 \%$ of our respondents experienced a period of hunger, $9 \%$ have lived without their father at age 10, and 5\% suffered from persecution and dispossession, respectively. We also included in our models an additional possible pathway—whether a respondent received immunizations as a child.

Table 7.A shows how micro channels are related to the experience of war. Males are both more likely to suffer from hunger and to be persecuted. The latter is what we expected given that mainly men were politically active during this period of time. Having experienced WWII increases the likelihood of experiencing hunger by about eight percentage points, ${ }^{9}$ dispossession and persecution by one percentage point, the absence of a father by two percentage points. These estimates are large relative increases given baseline risks. For 
example, the probability of experiencing hunger is doubled by war exposure and the probability of an absent dad is increased by $25 \%$ in relative terms. The experience of war was associated with a lower probability of immunization as a child, which is unsurprising given that this was wartime. This immunization result may be a pathway through which adult health eventually suffers.

In table 7.B our interest lies in whether the experience of combat is the mechanism that leads to war effects. Once again, the size of these estimates is very similar to those obtained by the country wartime variable. The experience of hunger and absence of the father is somewhat stronger for our respondents who lived in a region strongly affected by combat (3-10 months of combat) than for those in regions with none or only mild experience of combat. However, differences are not large. In fact, we expect the death of men during wartime to not necessarily happen in their region of residence. Persecution is related to war per se, but not necessarily to an increased experience of combat. Thus, combat does come with an increased likelihood of hunger as, for example, was the case in the Dutch hunger winter. It can be due to other aspects of war, as was the case for the Greek and German experience with hunger during WWII. Also, combat led to local deaths of the civilian population, but military casualties and the deaths of fathers often occur far from the families affected by it.

\section{E. The Uneven Consequences of War}

In addition to models summarized above, we investigated whether consequences of experiencing WWII vary by respondents' socio-economic status (SES) as a child by estimating models that included interactions of War variables with childhood SES.

Childhood SES is an index generated by factor analysis (Mazzonna, 2011). SES unifies four measures for SES during childhood at age 10. The variables are: logged proportion of number of room in the household and persons living in that household; logged number of books in the household; features in the household, namely warm water, cold water, fixed bath, toilet inside, central heating; and occupation of main breadwinner. For our analysis, we divide childhood SES status into three terciles and label those terciles low, middle, and high.

We separate our analysis of distributional consequences of WWII from our main analysis above since we recognize that childhood SES may partly be endogenous to WWII. Given the destructive scale of WW2 that included bombing that sometimes destroyed civilian homes and movement of men into the military, the possibility of such endogenity is clearly an important caveat to keep in mind. We did re-estimate all models in tables 5-7 with these

\footnotetext{
${ }^{9}$ Regarding the influence of hunger on late-life outcomes, we do not present structural estimates of the influence on late-life outcomes as there are no suitable instruments for the whole of Europe. These types of estimations are possible for a smaller set of countries. Van den Berg et al. (2011) use hunger periods caused by WWII for Greece, Germany, and the Netherlands as instruments to establish causal effects of under-nutrition on hypertension and adult height. For Germany, we collected data on monthly caloric rations in regions where respondents live. We see large drops in calories towards the end of the war and in occupation zones with the French and Soviet zone hit hardest. When we regress our health outcomes on average calories available between age 0 and 16 in respondents' region (again controlling for gender and year of birth), we find that an increase of $1000 \mathrm{kcal}$ per day decreases the chance of suffering from diabetes by 14.3 percentage points, increases SRH by 0.7 points, and increases height by 3.3 centimeters. When we distinguish different age groups $(0-4,5-10$, and 11-16), we see strongest results for $0-4$ group and impacts on adult depression. This suggests that hunger analysis should not only be seen as operating through nutrition-related outcomes such as adult height, but also and equally through adult outcomes such as depression. Our effects on height are similar to Van den Berg et al. (2011) who find an effect of between 3 and 6 centimeters.
} 
dummy variables for childhood SES terciles included and our estimates of the war barely changed.

Our distributional results are contained in table 8 . All models continue to contain country and year of birth dummies and a dummy for male. We include both main effects for experiencing war and for childhood SES being either low or middle class. To identify distributional effects of war, we include a full set of interactions of the war with childhood SES. Once again, the results obtained are very similar whether we use the war country variable or our combat variable so table 8 only displays the results for the war variable. The outcomes modeled are the same as those in tables 5-7-adult health, adult SES, and channels of war.

We first discuss main effects of childhood SES. Compared to those in the high childhood SES group, those in the lowest one have higher levels of adult diabetes (3.2 percentage points), are smaller in stature as adults (1.8 centimeters), experience higher levels of adult depression (2.5 percentage points), and self-rate themselves in worse adult subjective health. The middle childhood SES group consistently lies between the bottom and top in terms of these adult health outcomes. These results conform to the general finding in the literature that childhood economic circumstances are very predictive of later-life adult economic and health outcomes (Currie, 2009; Case et al., 2002; and Smith, 2009b). Similarly, in accordance with the literature, higher childhood SES is associated with much higher levels of adult education, net worth, and life satisfaction, another indication of the strong economic transmission across generations in these outcomes. The more novel results are in the third panel of table 8 which deals with the channels of war. The probability of being dispossessed was highest in the high childhood SES group, not surprising as there was more to capture. Persecution was also highest in the high SES category, while obtaining childhood immunizations was highest in the lowest SES category. Absent fathers were not strongly differentiated across SES categories.

Finally, we examine differences in associations with war by childhood SES categories. For childhood SES by WWII interactions among the health variables, we find the negative health effects to be either neutral by SES categories or that the negative health effects are concentrated on the middle class as in the summary measure of self-reported health or concentrated in the middle and lower class as with heart disease, possibly reflecting the role of lifetime stress with that disease.

In contrast, we find very strong interactions of a negative middle class war interaction for many of our adult SES outcomes-education, and ln net worth. Life satisfaction decrements associated with the war were concentrated on the lower and middle class. In terms of being ever married, the negative effects of the war were highest on the highest SES women and the lowest SES men. A summary of health and SES outcomes does suggest that the middle class suffered more due to the war with the lower class next in line. Finally, the length of time it takes to achieve a given level of education due to war expands the most for the low and middle class compared to the upper class. 
The bottom panel of table 8 shows that some pathways through which war operates are concentrated among the poorest households (hunger and immunizations (present for the middle class), some are concentrated among middle class (dad absent), or the highest SES households (dispossession). Persecution was focused on the middle and upper classes.

\section{Conclusions}

In this paper, we present a micro analysis of effects of WWII on some key SES and health outcomes of those experiencing the war. To conduct this analysis we use new dataSHARELIFE - that records not only adult outcomes in 2009, but also contains retrospective data for salient aspects of the wartime experiences of respondents. We augment these data with historical information on how WWII affected individuals differently over time and across regions. Our data allow us to analyze which type of individuals were most affected, and by which channels.

Our analysis shows that experiencing war increased the probability of suffering from diabetes, depression, and with less certainty heart disease so that those experiencing war or combat have significantly lower self-rated health as adults. Experiencing war is also associated with less education and life satisfaction, and decreases the probability of ever being married for women, while increasing it for men. We also analyze pathways through which these wartime effects took place and found strong effects for hunger, dispossession, persecution, childhood immunizations, and having an absent father. While a war of the magnitude of WWII affected all social classes to some degree, our evidence does suggest that the more severe effects were on the middle class with the lower class right below them in size of impact.

This paper highlights advantages of having life-histories in prospective studies such as SHARE. Population-based economic panels are relatively recent, but combining them with life-histories covering salient past personal and macro events opens up many new research opportunities of which WWII is only one illustration. This is especially so in Western Europe where the political and economic history of the past four decades is particularly rich and varied.

\section{Acknowledgments}

We would like to thank Alexander Danzer, Angus Deaton, Benjamin Friedman, Edward Glaeser, Dirk Jenter, Olmo Silva, Till von Wacher, participants of the conference on "Fetal Origins, Early Childhood Exposure, and Famine" at Princeton University, September 2011, as well as seminars audiences at Boston University, Harvard University, and the University of Cologne for helpful comments on earlier versions. Sarah Lehner and Johanna Sophie Quis provided excellent research assistance. Kesternich acknowledges financial support from the DFG through SFB/TR 15. Smith is supported by various grants from NIA. This paper uses data from SHARELIFE release 1, as of November 24th 2010 or SHARE release 2.5.0, as of May 24th 2011. The SHARE data collection has been primarily funded by the European Commission through the 5th framework and 6th framework program. SHARELIFE was supported through the 7th framework program. Additional funding from the U.S. National Institute on Aging as well as from various national sources is gratefully acknowledged.

\section{References}

Akbulut-Yuksel, Mevlude. IZA Discussion Paper No 4407. 2009. Children of the War: The Long-run Effects of Large-scale Physical Destruction and Warfare on Children. 
Acemoglu, Daron; Hassan, Tarek; Robinson, James. Social Structure and Development: A Legacy of the Holocaust in Russia. QJE. 2011; 126(2):895-946.

Almond, Douglas; Currie, Janet. Killing Me Softly - The Fetal Origins Hypothesis. Journal of Economic Perspectives. 2011; 25(3):153-172.

Auerbach, Hellmuth. Wolfgang Benz, Legenden, Lügen, Vorurteile. Ein Wörterbuch zur Zeitgeschichte, dtv. 1992. Opfer der nationalsozialistischen Gewaltherrschaft.

Banks, James; Muriel, Alastair; Smith, James P. Disease Prevalence, Disease Incidence, and Mortality in the United States and in England. Demography. 2010; 47:S211-S231. [PubMed: 21302425]

Brackman, Stephen; Garretsen, Harry; Schramn, Marc. The Strategic Bombing of German Cities during World War II and its Impact on City Growth. Journal of Economic Geography. 2004; 4(2): 201-218.

Case, Anne; Lubotsky, David; Paxson, Christina. Economic Status and Health in Childhood: The Origins of the Gradient. American Economic Review. 2002; 92(5):1308-1334.

Currie, Janet. Healthy, Wealthy, and Wise: Socioeconomic Status, Poor Health in Childhood, and Human Capital Development. Journal of Economic Literature. 2009; 47(1):87-122.

Deaton, Angus. Height, Health, and Development. PNAS. 2007; 104(33):13232-13237. [PubMed: 17686991]

Ellis, John. World War II - A Statistical Survey. London: Aurum Press; 1994.

Gimbel, John. The American Occupation of Germany: Politics and the Military, 1945-1949. 1. Palo Alto, CA: Stanford University Press; 1968.

Harrison, Mark. The Economics of World War II: Six Great Powers in International Comparison. Cambridge University Press; 1998. The Economics of World War II: An Overview; p. 1-42.

Heckman, James. The Developmental Origins of Health. Health Economics. 2012; 21(1):24-29. [PubMed: 22147625]

Hionidou, Violetta. Famine and Death in Occupied Greece, 1941-1944. Cambridge: Cambridge University Press; 2006.

Ichino, Andrea; Winter-Ebmer, Rudolf. The Long-Run Educational Cost of World War II. Journal of Labor Economics. 2004; 22(1):57-87.

Jürges, Hendrik. Collateral Damage: Educational Attainment and Labor Market Outcomes among German War and Post-war Cohorts. 2011. unpublished manuscript

Kulischer, Eugene M. Europe on the Move: War and Population Changes, 1917-1947. New York: Columbia University Press; 1948.

Maddison, Angus. Historical Statistics: Statistics on World Population, GDP and Per Capita GDP. 2008; 1 http://www.ggdc.net/MADDISON/oriindex.htm.

Mazzonna, Fabrizio. (MEA) Discussion Paper 245-11. 2011. The Long-Lasting Effects of Family Background: A European Cross-Country Comparison.

Neelsen, Sven; Stratman, Thomas. Effects of Prenatal and Early Life Malnutrition: Evidence from the Greek Famine. Journal of Health Economics. 2011; 30(3):479-488. [PubMed: 21546107]

Neugebauer, Richard; Hoek, Hans Wijbrand; Susser, Ezra. Prenatal Exposure to Wartime Famine and Development of Antisocial Personality Disorder in Early Adulthood. JAMA. 1999; 282(5):455462. [PubMed: 10442661]

Overman, Rüü. Deutsche Militaerische Verluste im 2 Weltkrieg. Oldenburg Verlag; 1999.

Putzger, Friedrich Wilhelm. Historischer Weltatlas. Velhagen \& Klasing; 1963.

de Rooij, Suzanne R.; Wouters, Hans; Yonker, Julie E.; Painter, Rebecca C.; Roseboom, Tessa J. Prenatal Undernutrition and Cognitive Function in Late Adulthood. PNAS, Proceedings of the National Academy of Sciences USA. 2010; 107(39):16881-16886.

SHARE Release Guide 2.5.0 for Waves 1 \& 2. 2011. http://www.share-project.org/sharelife/

SHARELIFE Release Guide 1. 2010. http://www.share-project.org/sharelife/

Smith, James P. Nature and Causes of Male Diabetes Trends, Undiagnosed Diabetes, and the SES Health Gradient. PNAS. 2007; 104(33):3,225-13,231. [PubMed: 17190800]

Smith, James P. The Impact of Childhood Health on Adult Labor Market Outcomes. The Review of Economics and Statistics. 2009a; 91(3):478-489. [PubMed: 23585697] 
Smith, James P. Re-constructing Childhood Health Histories. Demography. 2009b; 46(2):387-403. [PubMed: 21305399]

Kaiserliches Statistisches Amt. Berlin: Puttkammer \& Mühlbrecht; 1909-1939. Statistisches Jahrbuch für das Deutsche Reich (Statistical Yearbook).

Statistisches Bundesamt. Statistisches Jahrbuch für die Bundesrepublik Deutschland. Stuttgart: W. Kohlhammer; 1952, 1953.

Van den Berg, Gerard; Pinger, Pia A.; Schoch, Johannes. IZA Discussion Paper No 6110. 2011. Instrumental Variable Estimation of the Causal Effect of Hunger Early in Life on Health Later in Life.

Van Mourik, W. Bilanz des Krieges. Rotterdam: Lekturama; 1978.

Waldinger, Fabian. The Role Human and Physical Capital for the Creation of Scientific Knowledge. University of Warwick; 2012. Bombs, Brains, and Science.

Wehler, Hans-Ulrich. Deutsche Gesellschaftsgeschichte 1914-1949. München: C. H. Beck; 2008.

Zink, Harold. The United States in Germany 1944-1955. Princeton, NJ: D. Van Nostrand; 1957.

\section{Appendix Table A.—External Data Variable Definitions}

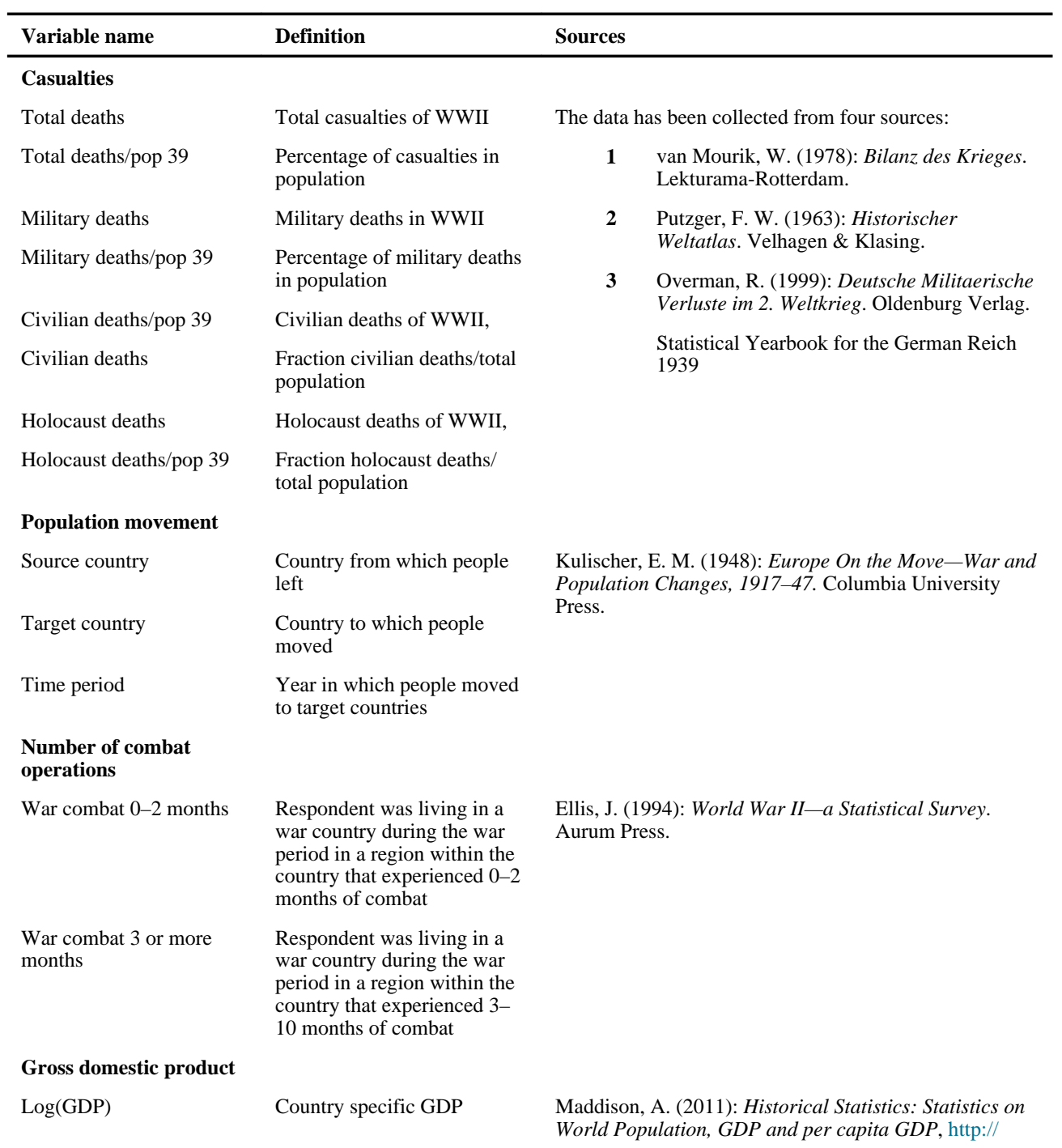




\begin{tabular}{lll}
\hline Variable name & Definition & Sources \\
\hline & & $\begin{array}{l}\text { www.ggdc.net/MADDISON/oriindex.htm (accessed } \\
\text { June, 2011). }\end{array}$ \\
Sex ratio & \\
Sex ratio & $\begin{array}{l}\text { Ratio of men to women for } \\
\text { time periods before and after } \\
\text { war }\end{array}$ & $\begin{array}{l}\text { Statistical Yearbooks for Germany, chapter "Bewegung } \\
\text { und Bevölkerung", and "Internationale Übersichten", } \\
1909-1939 \text { and 1945-53 }\end{array}$ \\
\hline
\end{tabular}

\section{Appendix Table B.-Descriptive Statistics}

\begin{tabular}{|c|c|c|c|c|c|c|c|}
\hline & \multirow{2}{*}{$\begin{array}{c}\text { Percentage Missing } \\
\text { Observations }\end{array}$} & \multicolumn{2}{|c|}{ 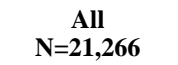 } & \multicolumn{2}{|c|}{$\begin{array}{c}\text { War }=0 \\
N=11,411\end{array}$} & \multicolumn{2}{|c|}{$\begin{array}{c}\text { War }=1 \\
N=9,855\end{array}$} \\
\hline & & Mean & S.D. & Mean & S.D. & Mean & S.D. \\
\hline \multicolumn{8}{|l|}{ Background information } \\
\hline Year of birth & 0.000 & 1942 & 9.52 & 1947 & 8.07 & 1936 & 7.13 \\
\hline Male & 0.000 & 0.45 & 0.50 & 0.45 & 0.50 & 0.46 & 0.50 \\
\hline Childhood SES & 0.034 & 0.02 & 1.00 & 0.22 & 0.99 & -0.21 & 0.96 \\
\hline \multicolumn{8}{|l|}{ Outcome measures } \\
\hline Depression & 0.000 & 0.36 & 0.48 & 0.34 & 0.47 & 0.38 & 0.48 \\
\hline Diabetes & 0.002 & 0.10 & 0.30 & 0.07 & 0.25 & 0.13 & 0.34 \\
\hline Ever married & 0.000 & 0.94 & 0.23 & 0.93 & 0.25 & 0.95 & 0.22 \\
\hline Heart disease & 0.002 & 0.12 & 0.32 & 0.08 & 0.27 & 0.16 & 0.37 \\
\hline Height & 0.007 & 168.31 & 8.85 & 169.47 & 8.92 & 166.97 & 8.59 \\
\hline Life satisfaction & 0.081 & 7.60 & 1.72 & 7.87 & 1.62 & 7.29 & 1.79 \\
\hline $\log$ (net worth) & 0.040 & 12.45 & 1.87 & 12.94 & 1.83 & 11.88 & 1.75 \\
\hline Self-rated-health & 0.001 & 2.80 & 1.07 & 3.03 & 1.07 & 2.53 & 1.01 \\
\hline Years of education & 0.080 & 10.72 & 4.16 & 11.71 & 3.88 & 9.56 & 4.18 \\
\hline Education Diff in Years & 0.466 & 0.42 & 2.91 & 0.51 & 2.78 & 0.34 & 3.03 \\
\hline \multicolumn{8}{|l|}{ Channels of war exposure } \\
\hline Dad absent & 0.017 & 0.09 & 0.28 & 0.07 & 0.25 & 0.10 & 0.31 \\
\hline Dispossession & 0.001 & 0.03 & 0.18 & 0.02 & 0.15 & 0.04 & 0.21 \\
\hline Hunger & 0.001 & 0.07 & 0.25 & 0.02 & 0.14 & 0.13 & 0.33 \\
\hline Persecution & 0.001 & 0.04 & 0.19 & 0.03 & 0.18 & 0.04 & 0.21 \\
\hline Childhood Immunizations & 0.012 & 0.95 & 0.23 & 0.98 & 0.15 & 0.91 & 0.29 \\
\hline
\end{tabular}

See table 1 for definitions of variables in first column and Appendix table A for definition of War combat variable. 
Figure 1.A.

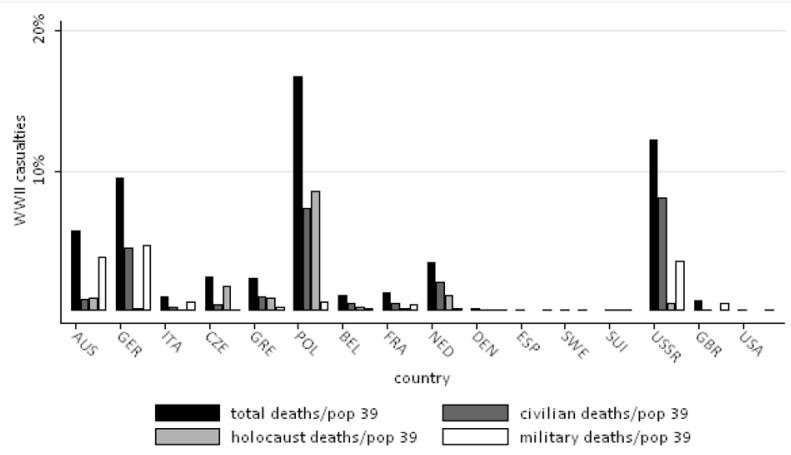

Figure 1.B.

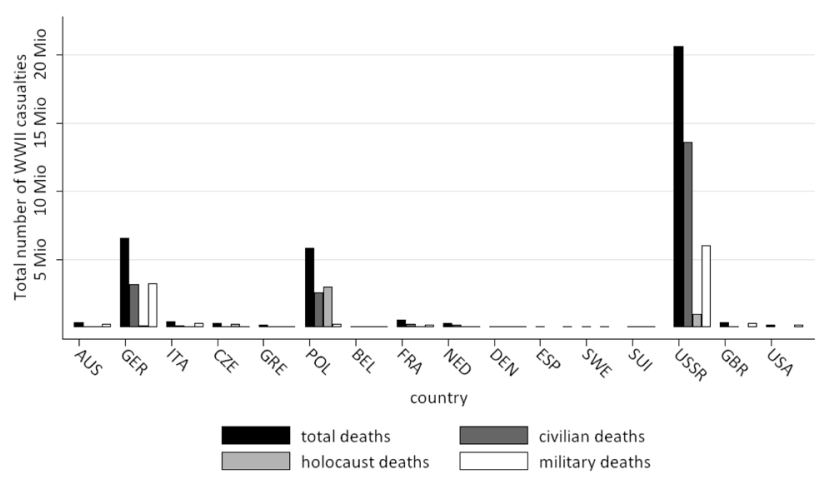

Figure 1.

Figure 1.A.-WWII Casualties as Percent of the Population

Figure 1.B.- Total Number of WWII Casualties in the Population 

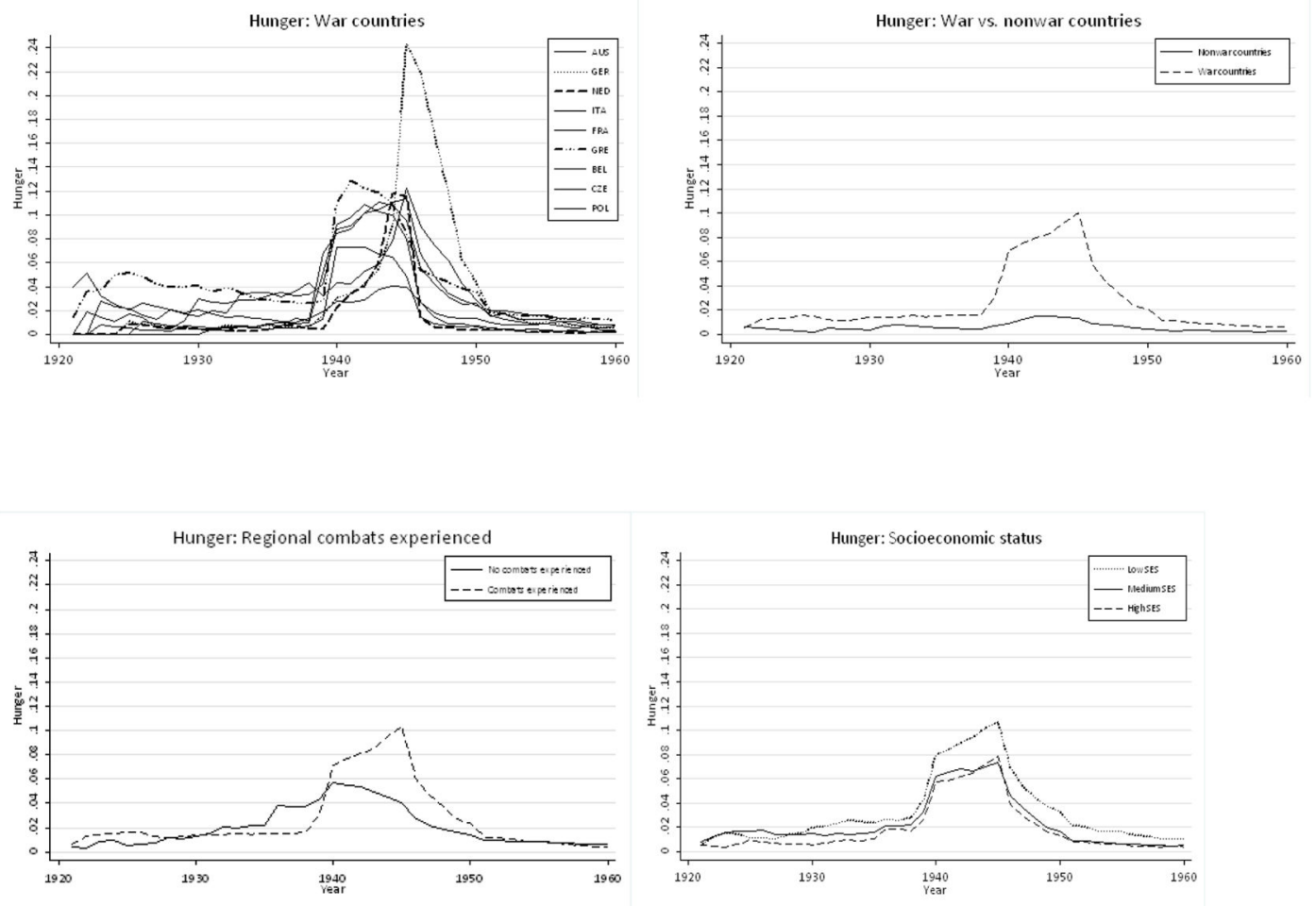

Figure 2.

Percentage of SHARE Respondents Suffering from Hunger: War versus Non-war 

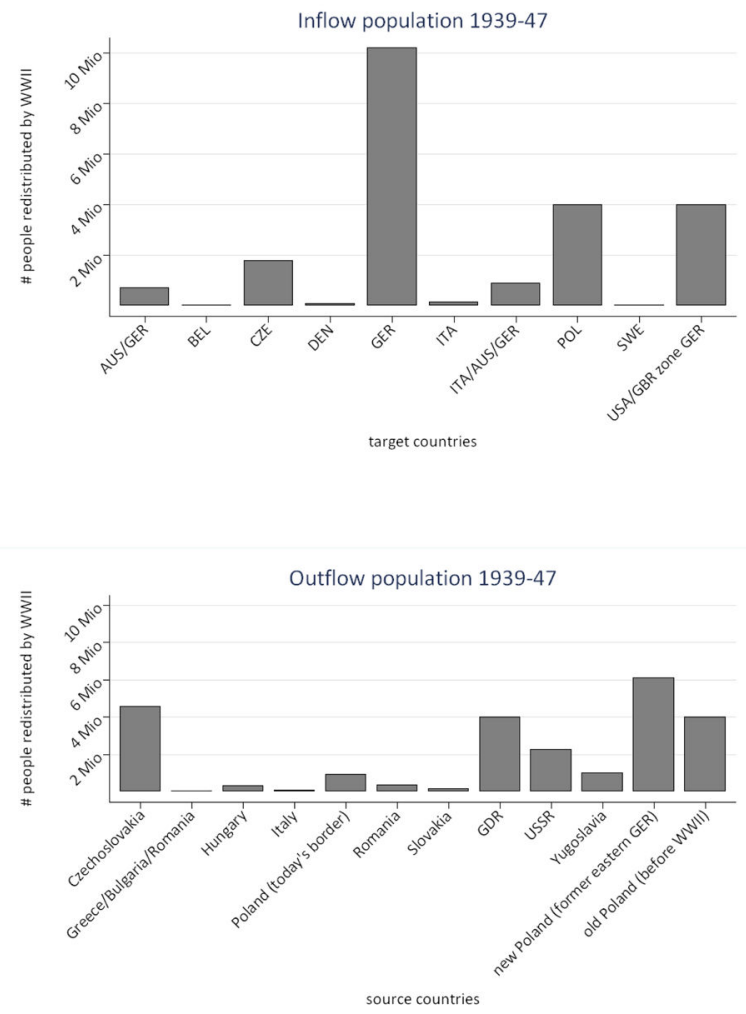

Figure 3.

Total Inflow and Outflow of Population 1939-1947 


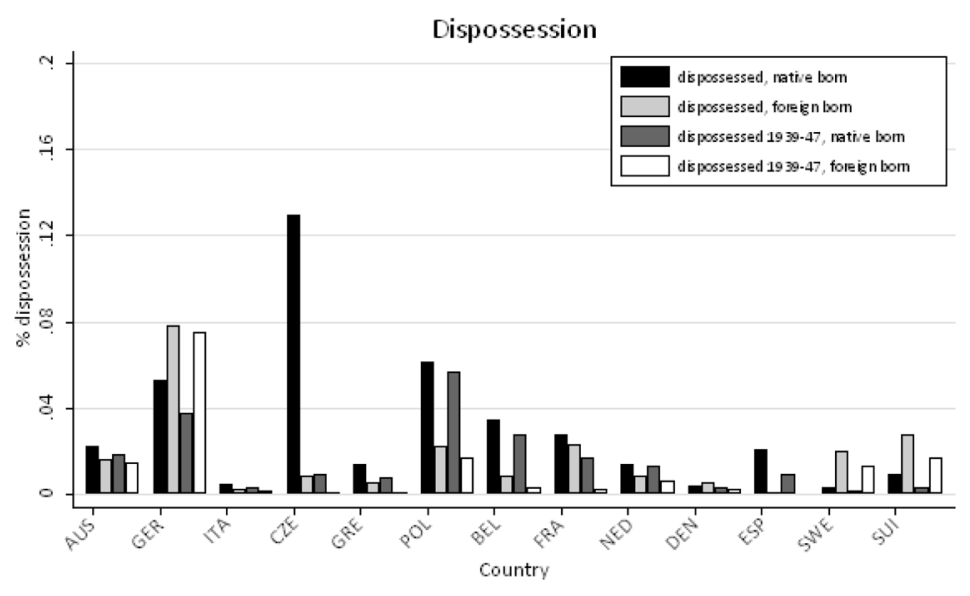

Figure 4.

Dispossession of Population in WWII 

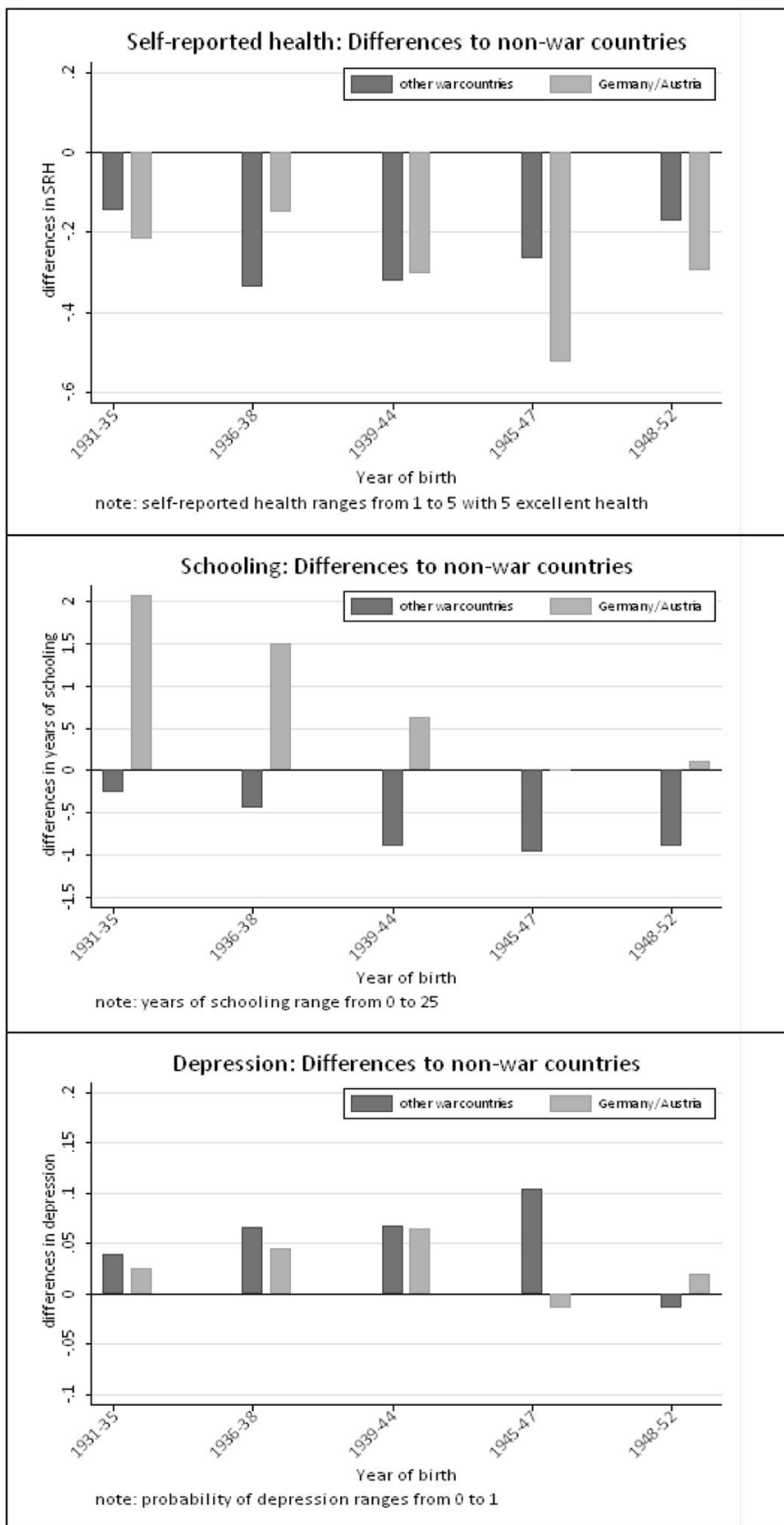

Figure 5 .

Later Life Outcome Differences between War and Non-War Countries by Period of Birth 


\section{Table 1}

\section{Variable Definitions}

\begin{tabular}{|c|c|}
\hline Variable name & Definition \\
\hline \multicolumn{2}{|l|}{ Background information } \\
\hline Year of birth & Year of birth \\
\hline Male & Dummy $=1$ if respondent is male \\
\hline Childhood SES & $\begin{array}{l}\text { Unifies four measures for SES at age 10: Logged number of books in household; logged number of rooms and } \\
\text { persons in household; features in household; occupation of main breadwinner }\end{array}$ \\
\hline \multicolumn{2}{|l|}{ Outcome measures } \\
\hline Childhood Immunizations & Dummy $=1$ if respondent got any vaccinations during childhood \\
\hline Depression & Dummy $=1$ if respondent suffers from more than three depression symptoms in EURO-D scale \\
\hline Diabetes & Dummy $=1$ if respondents has diabetes or high blood sugar \\
\hline Ever married & Dummy $=1$ if respondents was ever married \\
\hline Heart disease & Dummy = 1 if respondent has heart problems (including heart attack) \\
\hline Height & Height in $\mathrm{cm}$ \\
\hline Life satisfaction & Life satisfaction on a scale from $0-10$ with 0 very unsatisfied and 10 very satisfied \\
\hline $\log ($ net worth) & $\begin{array}{l}\text { Logged household net worth as the sum of values from bank accounts, bonds, stocks, mutual funds, retirement } \\
\text { accounts, contractual savings and life insurances minus liabilities }\end{array}$ \\
\hline Self-rated health & Categorical variable for self-rated health with excellent health $=5$ \\
\hline Years of education & Years of education \\
\hline \multicolumn{2}{|l|}{ Channels of war exposure } \\
\hline Dad absent & Dummy $=1$ if biological father was absent at the age of 10 \\
\hline Dispossession & Dummy = 1 if respondent reports ever being dispossessed \\
\hline Hunger & Dummy $=1$ if respondent ever suffered hunger and when \\
\hline Persecution & Dummy $=1$ if respondent reports ever being persecuted \\
\hline \multicolumn{2}{|l|}{ War variables } \\
\hline War & Dummy $=1$ if respondent was living in a war country during the war period \\
\hline War combat $0-2$ months & $\begin{array}{l}\text { Respondent was living in a war country during the war period in a region within the country that experienced } 0-2 \\
\text { months of combat }\end{array}$ \\
\hline War combat 3-10 months & $\begin{array}{l}\text { Respondent was living in a war country during the war period in a region within the country that experienced } 3-10 \\
\text { months of combat }\end{array}$ \\
\hline
\end{tabular}

Rev Econ Stat. Author manuscript; available in PMC 2014 May 19. 


\section{Table 2}

GDP per Head Relative to US GDP per Head

\begin{tabular}{ccccc}
\hline Country & $\mathbf{1 9 3 8}$ & $\mathbf{1 9 5 0}$ & $\mathbf{1 9 7 3}$ & $\mathbf{1 9 8 7}$ \\
\hline UK & .98 & .72 & .72 & .73 \\
Germany & .84 & .45 & .79 & .82 \\
France & .72 & .55 & .78 & .78 \\
Italy & .53 & .36 & .63 & .70 \\
Japan & .38 & .20 & .66 & .77 \\
USSR & .35 & .30 & .36 & .33 \\
\hline
\end{tabular}

Source: Harrison (1998), Table 1-10. 


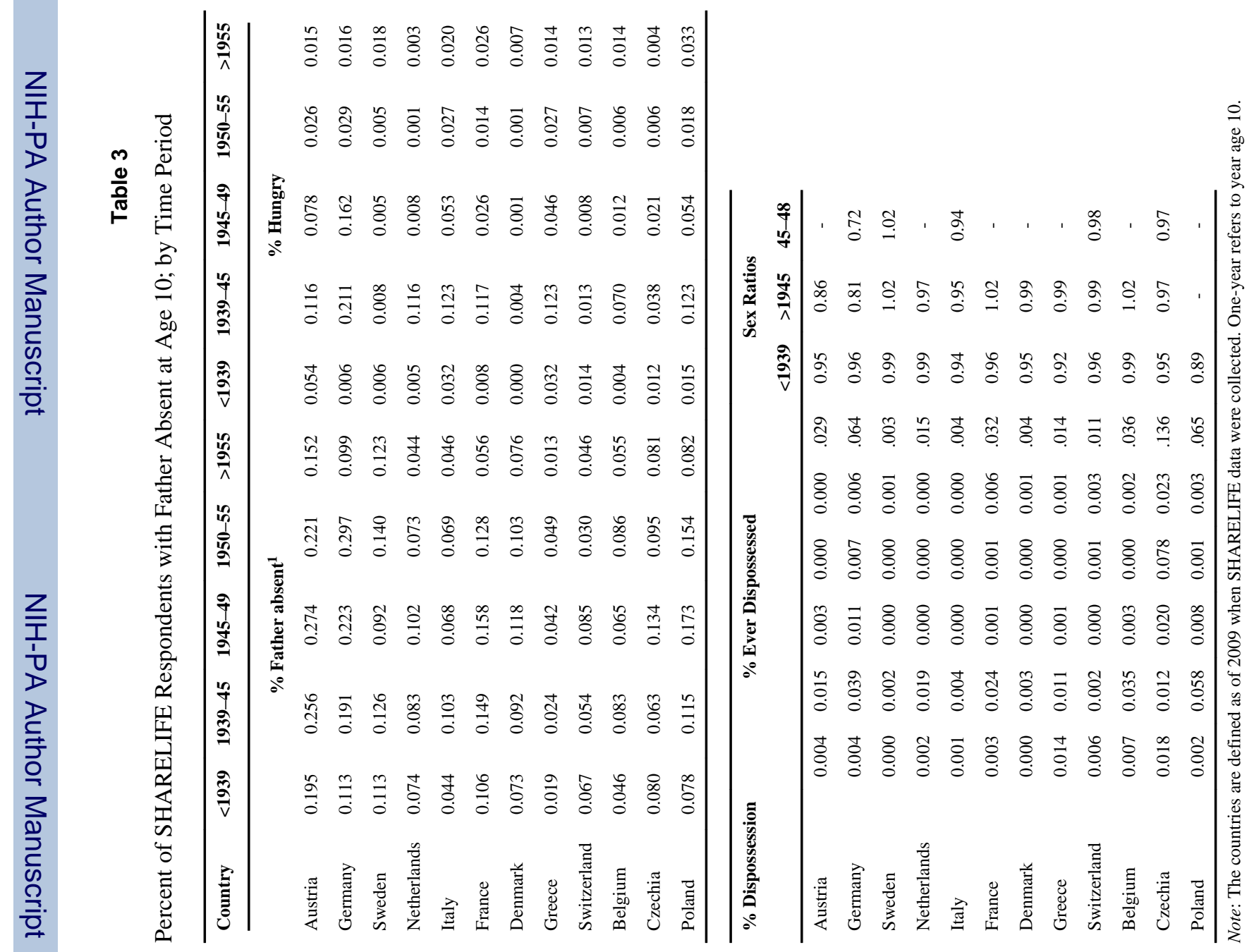


Table 4

Number of Observations Available in SHARELIFE; by Country

\begin{tabular}{lrrr}
\hline Observations Country & War = 0 & War = 1 & Total \\
\hline Austria & 146 & 565 & 711 \\
Germany & 450 & 1,001 & 1,451 \\
Italy & 863 & 1,470 & 2,333 \\
Czechia & 723 & 925 & 1,648 \\
Greece & 1,149 & 1,482 & 2,631 \\
Poland & 819 & 758 & 1,577 \\
Belgium & 1,026 & 1,480 & 2,506 \\
France & 793 & 1,105 & 1,898 \\
Netherlands & 883 & 1,069 & 1,952 \\
Denmark & 1,927 & 0 & 1,927 \\
Sweden & 1,639 & 0 & 1,639 \\
Switzerland & 993 & 0 & 993 \\
\hline Total & 11,411 & 9,855 & 21,266 \\
\hline
\end{tabular}

Note: The countries are defined as of 2009 when the SHARELIFE data were collected. Native born only. War = 1 means that the respondent was living in a war country sometime during World War II.

Source: SHARELIFE; calculations by authors. 


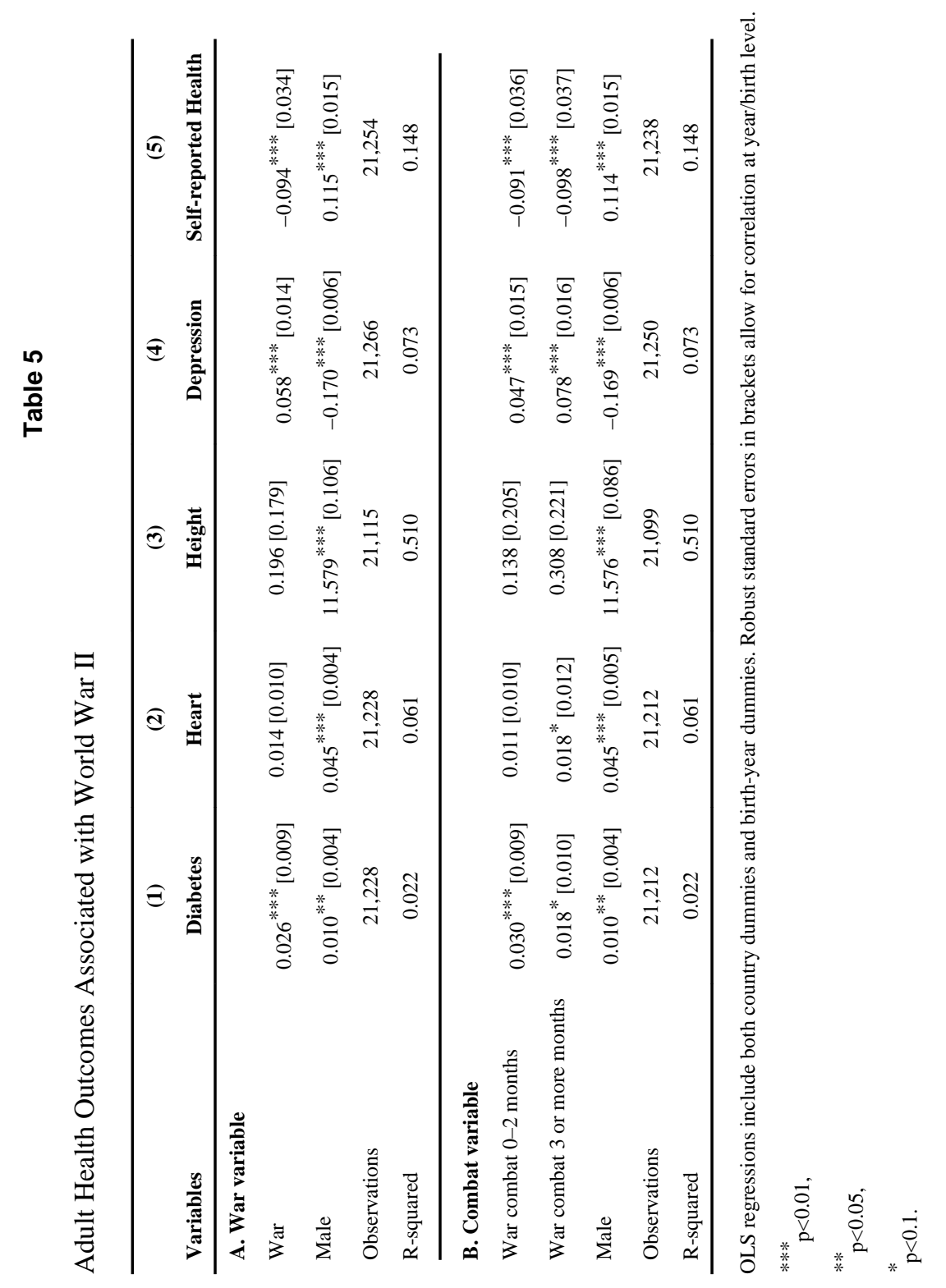

Rev Econ Stat. Author manuscript; available in PMC 2014 May 19. 


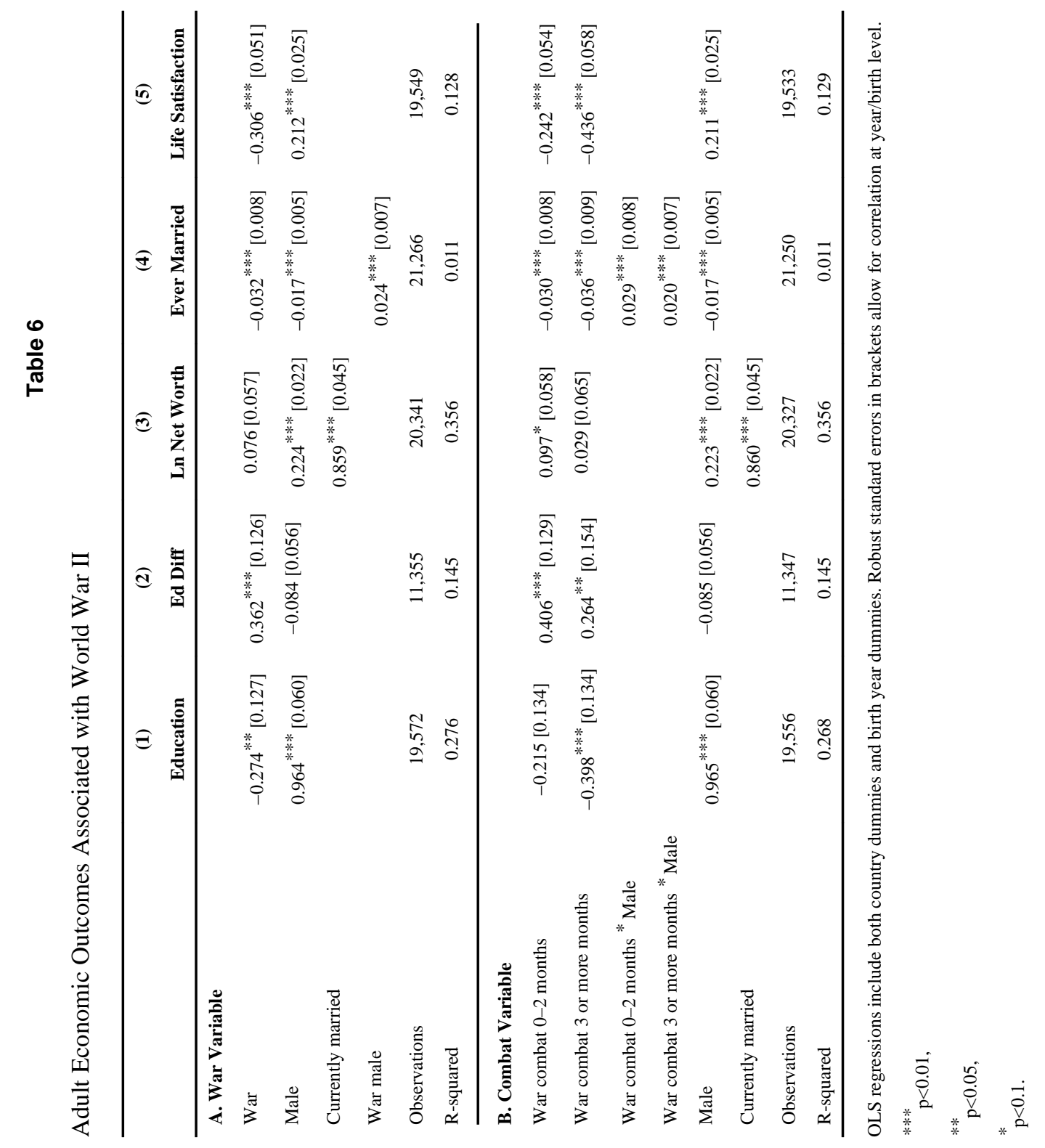




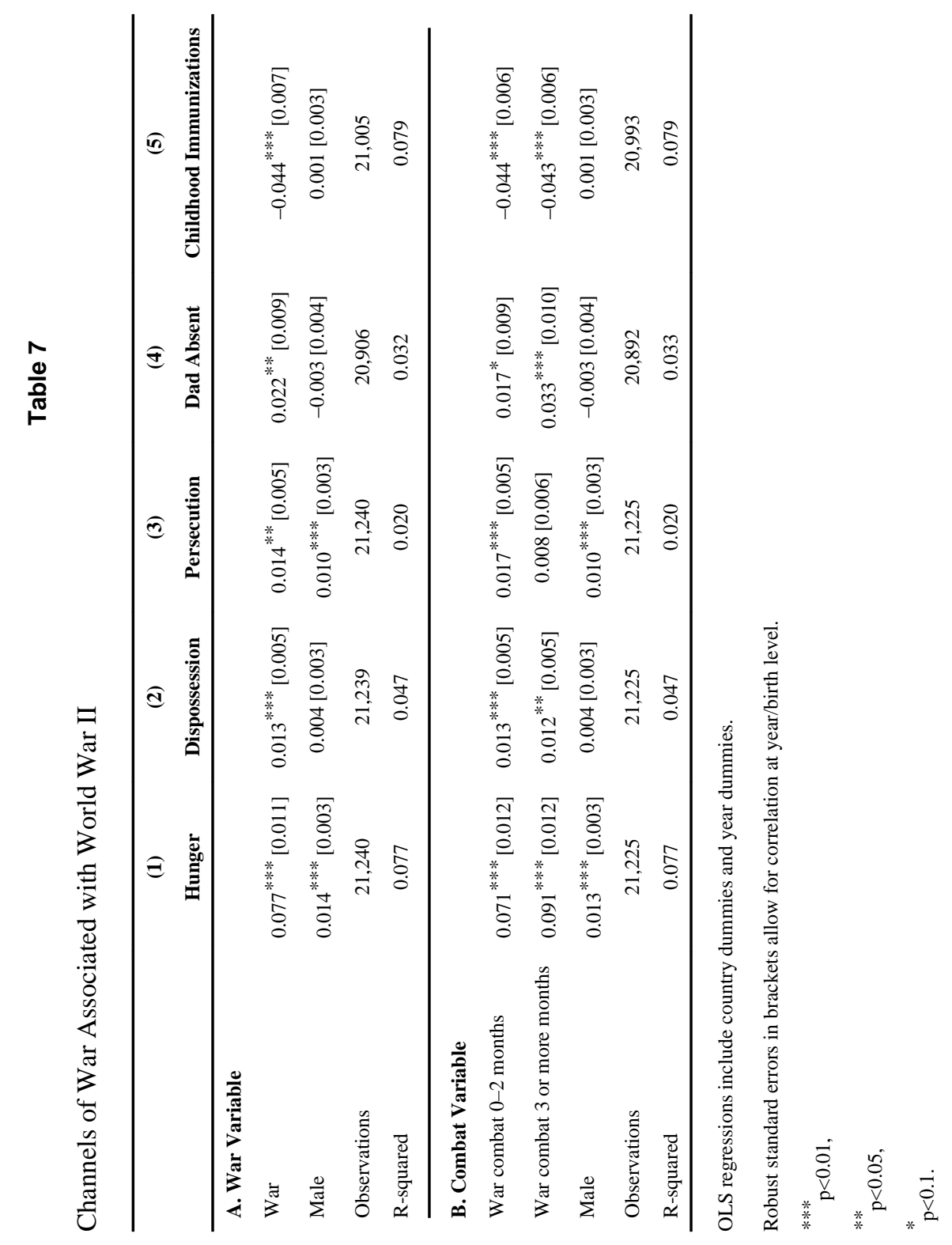




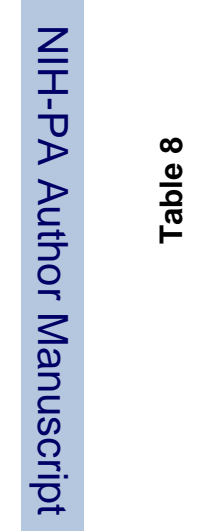

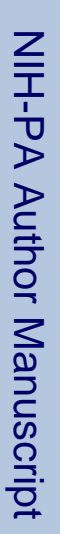

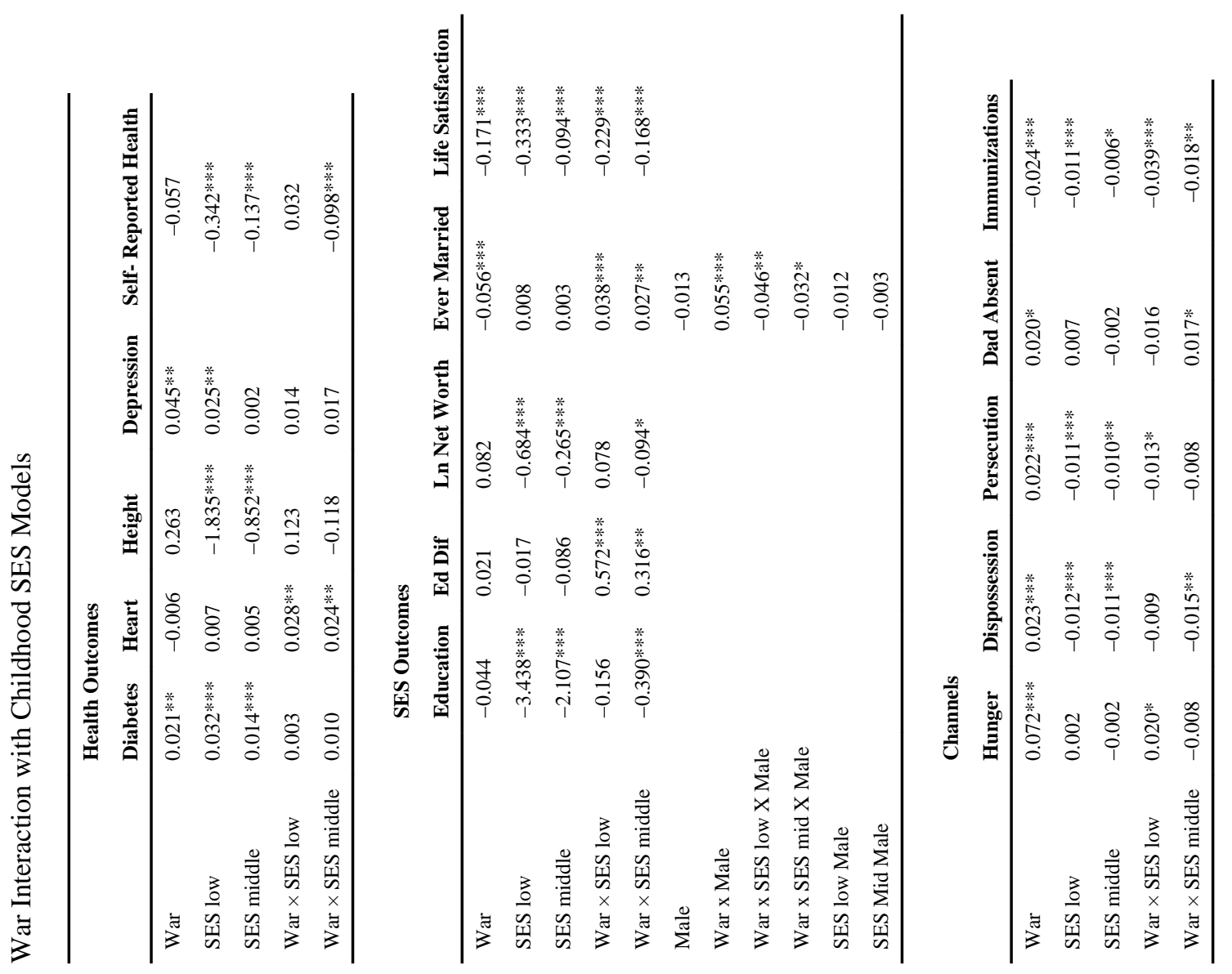

Rev Econ Stat. Author manuscript; available in PMC 2014 May 19. 